\title{
Downregulation of STEAP4, a highly-expressed TNF- $\alpha$-inducible gene in adipose tissue, is associated with obesity in humans ${ }^{1}$
}

\author{
Chun-mei ZHANG ${ }^{2,3,4}, \mathrm{Xia}^{2} \mathrm{CHI}^{2,3,4}$, Bin WANG ${ }^{2,3}$, Min ZHANG ${ }^{2,3}$, Yu-hui $\mathrm{NI}^{2,3}$, Rong-hua $\mathrm{CHEN}^{3}$, Xiao-nan $\mathrm{LI}^{2,3,5}$, Xi-rong \\ $\mathrm{GUO}^{2,3,5}$
}

${ }^{2}$ Department of Pediatrics, Nanjing Maternal and Child Health Hospital of Nanjing Medical University, Nanjing 210004 , China; ${ }^{3}$ Institute of Pediatrics, Nanjing Medical University, Nanjing 210029, China

\section{Key words}

six-transmembrane epithelial antigen of the prostate 4; obesity; tumor necrosis factor- $\alpha$ adipose tissuess

${ }^{1}$ Project supported by grants from the National Natural Science Foundation of China (No 30772364), the Natural Science Foundation of Jiangsu Province, China (No BK2007230), the Foundation of Ministry of Education, China (No 20070312001), and Nanjing Medical University (No 07NMUZ024).

${ }^{4}$ These authors contributed equally to this work.

${ }^{5}$ Correspondence to Dr Xi-rong GUO and Dr Xiao-nan LI

Phn 86-25-8686-2996.

E-mailxrguo@njmu.edu.cn (Xi-rong GUO) Phn 86-25-8686-2996.

E-mailxnli@njmu.edu.cn (Xiao-nan LI)

Received 2007-11-20

Accepted 2008-02-25

doi: $10.1111 /$ j.1745-7254.2008.00793.x

\begin{abstract}
Aim: To determine the relationship between six-transmembrane epithelial antigen of the prostate 4 (STEAP4) expression and obesity. Methods: RT-PCR and immunoblot analyses were performed to determine the differential expressions of STEAP4 mRNA and protein, respectively, in human omental adipose tissue from obese patients and normal weight controls. The expression pattern of STEAP4 mRNA in various human tissues was determined by RT-PCR. The subcellular localization of the STEAP4 protein in human adipose tissue was confirmed by immunohistochemistry. Finally, we confirmed that cultured human omental adipose tissue undergoes TNF- $\alpha$-mediated regulation of the STEAP4 expression. Results: STEAP4 mRNA and protein levels were downregulated in omental adipose tissue from obese patients relative to normal controls. The STEAP4 expression was most abundant in human adipose tissue. An immunohistochemical analysis confirmed that STEAP4 was associated with the plasma membrane of adipocytes. The STEAP4 expression was induced by TNF- $\alpha$ in a dose-dependent manner in human adipose tissue. Conclusion: STEAP4 was abundantly expressed in human adipose tissue, and the STEAP4 expression was significantly downregulated in obese patients. STEAP4 localized to the plasma membrane of adipocytes, and the STEAP4 expression was induced by TNF- $\alpha$ in adipose tissue. These data suggest that STEAP4 may play a significant role in the development of human obesity.
\end{abstract}

\section{Introduction}

Obesity is a multifactorial disease resulted from interactions between susceptibility genes and environmental factors. Furthermore, obesity is an important risk factor for other diseases, including type 2 diabetes, hypertension, hyperlipidemia, and cardiac infarction ${ }^{[1-3]}$. During the development of obesity, adipose tissue plays a key role in energy homeostasis by regulating the balance between energy storage and energy consumption in response to nutritional status $^{[1]}$. Therefore, the identification and functional characterization of genes whose expression is differentially regulated in obese patients relative to normal weight controls may provide new insights into the molecular mechanisms underlying obesity-associated pathogenesis.
In a previous study, we performed suppression subtractive hybridization ${ }^{[4-5]}$ using omental adipose tissue from obese patients and normal weight controls. We identified 426 differentially-expressed genes in adipose tissue from obese patients. In total, 216 genes were upregulated and 210 genes were downregulated $^{[6]}$. Among these genes, we found that the expression of six-transmembrane epithelial antigen of the prostate (STEAP) 4, a member of the STEAP protein family, was significantly downregulated in the obese patients, suggesting that STEAP4 may be associated with obesity. Although a previous study had shown an association between STEAP4 overexpression and human prostate cancer ${ }^{[7]}$, a link between human STEAP4 and obesity had not been reported. Studies of the mouse homolog of STEAP4, six-transmem- 
brane protein of prostate (STAMP) 2 [previously called tumor necrosis factor (TNF)- $\alpha$-induced adipose-related protein], which shares $90 \%$ amino acid identity with human STEAP4, showed TNF- $\alpha$-mediated STAMP2 induction and adipose conversion ${ }^{[8]}$. Recently, Wellen et al identified STAMP2 as a critical modulator of inflammation and nutrition, suggesting a potential role for STEAP4 in human obesity ${ }^{[9]}$.

In the present study, we determined the relationship between human STEAP4 and obesity. We analyzed: the differential expression of STEAP4 in adipose tissue from obese patients relative to normal controls, the STEAP4 expression in a panel of human tissues, the subcellular localization of STEAP4 in human adipose tissue, and the TNF- $\alpha$-mediated induction of STEAP4 in human adipose tissue. Taken together, these findings are in agreement with previous studies of mouse STAMP2 and suggest that STEAP4 is likely to play a significant role in the development of human obesity.

\section{Materials and methods}

Antibody preparation Rabbit polyclonal antiserum was generated against an N-terminal peptide of STEAP4 (AEYLAHLVPGAHVVKAC), coupled to bovine serum albumin and subjected to antigen affinity purification (GL Biochem, Shanghai, China).

Analysis of the differential expressions of STEAP4 mRNA and protein All human omental adipose tissues were obtained from male patients undergoing abdominal surgery for acute simple appendicitis. Patients were assigned to the normal weight group or obese group according to their body mass index (BMI) ${ }^{[10]}$, which was defined as weight in kilograms divided by the square of height in meters. When patients' $\mathrm{BMI}=30 \mathrm{~kg} / \mathrm{m}^{2}$, they were assigned to the obese group ( $n=6$; BMI 30.3 \pm 0.3 ; age 50.6 \pm 9.2 ); when BMI scores fell between 18 and $25 \mathrm{~kg} / \mathrm{m}^{2}$, the patients were assigned to the normal group ( $n=6$; BMI 22.2 \pm 1.7 ; age 47.1 \pm 11.7 ). Written consent was obtained from each patient, and the experiments were conducted according to the Declaration of Helsinki.

The differential expression of STEAP4 mRNA was analyzed using RT-PCR. Total RNA from the omental adipose tissues of obese and normal weight patients was extracted using Trizol reagent (Invitrogen, Carlsbad, CA, USA). Total RNA samples (200 ng) were subjected to RT-PCR using random primers with Moloney murine leukemia virus reverse transcriptase (Promega, Madison, WI, USA), and an aliquot $(10 \%)$ of the resulting cDNA was amplified using GAPDH and STEAP4-specific primers. The primer sequences for STEAP4 and GAPDH were as follows: STEAP4, 5'-
CGAAACTTC CCTCTACCCG-3' (sense) and 5'ACACAAACACCTGCCGACTT-3' (antisense); GAPDH, 5'TGAAGGTCGGAGTCAACGGATTTGGT-3' (sense) and 5'CATGTGGGCCATGAGGTCCACCAC-3' (antisense). After denaturation at $94{ }^{\circ} \mathrm{C}$ for $3 \mathrm{~min}, 34$ cycles of PCR amplification were performed $\left(30 \mathrm{~s}\right.$ at $94{ }^{\circ} \mathrm{C}, 30 \mathrm{~s}$ at $58^{\circ} \mathrm{C}$, and $40 \mathrm{~s}$ at $72^{\circ} \mathrm{C}$ ). A final extension step was performed at $72{ }^{\circ} \mathrm{C}$ for 7 min. Finally, $5 \mu \mathrm{L}$ of the PCR product was loaded on a $1.5 \%$ agarose gel.

The STEAP4 protein expression was analyzed by immunoblotting, as described previously ${ }^{[6]}$. Briefly, approximately $100 \mathrm{mg}$ of fresh or frozen adipose tissue was resuspended in $1 \mathrm{~mL}$ lysis buffer $(50 \mathrm{mmol} / \mathrm{L}$ Tris- $\mathrm{HCl}, 1 \%$ Triton $\mathrm{X}-100,0.2 \%$ sodium deoxycholate, $0.2 \% \mathrm{SDS}$, and $1 \mathrm{mmol} / \mathrm{L}$ EDTA at $\mathrm{pH}$ 7.4) and homogenized using a polytron homogenizer at $4{ }^{\circ} \mathrm{C}$. The lysate supernatant was collected after centrifugation at $20670 \times g$ for $30 \mathrm{~min}$ at $4{ }^{\circ} \mathrm{C}$. Protein concentrations were determined using a bicinchoninic acid protein assay kit (Pierce, Rockford, IL, USA), and $30 \mu \mathrm{g}$ of total protein was loaded in each lane of a $10 \%$ polyacrylamide gel, followed by SDS-PAGE. Prestained protein standards (Fermentas, Hanover, MD, USA) were used as molecular weight markers. The separated proteins were electrophoretically transferred to a nitrocellulose membrane filter (Whatman, $\mathrm{GmbH}$, Dassel, Germany), and the membrane was blocked with $5 \%$ dried milk for $2 \mathrm{~h}$ at room temperature. Subsequently, the membranes were incubated at $4{ }^{\circ} \mathrm{C}$ overnight in a primary antibody (polyclonal rabbit anti-STEAP4 antibody or monoclonal mouse anti-GAPDH antibody; KangChen Bio-tech, Shanghai, China) at an appropriate dilution, followed by incubation with horseradish peroxidase (HRP)-conjugated secondary antibodies (Santa Cruz Biotechnology, Santa Cruz, CA, USA) for $1 \mathrm{~h}$ at room temperature. STEAP4 and GAPDH bands were detected using enhanced chemiluminescence reagents (Amersham, Piscataway, NJ, USA) and hyperfilm exposure.

Analysis of STEAP4 expression in a panel of human tissues RT-PCR was performed using specific primer pairs to amplify human STEAP4 and GAPDH (primer sequences given earlier) in a panel of human tissues. We purchased the human multiple tissue cDNA (MTC) panel I (Clontech, Mountain View, California, USA). The adipose tissue cDNA sample was prepared manually from normal weight human omental adipose tissue obtained with prior consent during abdominal surgery for appendicitis. The human normal testis and spleen cDNA samples were purchased from Bio/Biotech (Shanghai, China). All PCR reactions were performed using the following protocol: denaturation at $94{ }^{\circ} \mathrm{C}$ for $30 \mathrm{~s}$, followed by 35 amplification cycles $\left(30 \mathrm{~s}\right.$ at $94^{\circ} \mathrm{C}, 30 \mathrm{~s}$ at $60^{\circ} \mathrm{C}$, 
and $40 \mathrm{~s}$ at $72{ }^{\circ} \mathrm{C}$ ), and a final extension at $72{ }^{\circ} \mathrm{C}$ for $5 \mathrm{~min}$. Negative controls (no cDNA template) were included with both the GAPDH- and STEAP4-specific primer reactions. Gel analysis was performed using aliquots removed at cycle 22 for GAPDH and at cycle 34 for STEAP4; $5 \mu \mathrm{L}$ of the amplification product was loaded on a $1.5 \%$ agarose gel.

Immunohistochemistry Human omental adipose tissues were fixed at $4{ }^{\circ} \mathrm{C}$ overnight with $4 \%$ paraformaldehyde in 0.1 $\mathrm{mol} / \mathrm{L}$ phosphate buffer at $\mathrm{pH} 7.2$ and embedded in paraffin. Next, $5 \mu \mathrm{m}$-thick sections were cut and mounted onto microscope slides. The sections were deparaffinized with xylene and hydrated in graded ethanol. After deparaffinization, the sections were subjected to antigen retrieval in $0.01 \mathrm{~mol} / \mathrm{L}$ sodium citrate at $\mathrm{pH} 6.0$ at $100{ }^{\circ} \mathrm{C}$ for $10 \mathrm{~min}$ in a microwave oven. They were then incubated at $4{ }^{\circ} \mathrm{C}$ overnight with a polyclonal anti-STEAP4 antibody (1:100 dilution). After washing with phosphate-buffered saline, the sections were treated with a goat antirabbit HRP-conjugated secondary antibody (1:100 dilution) at $37{ }^{\circ} \mathrm{C}$ for $1 \mathrm{~h}$. The primary antibody was detected using a diaminobenzidine (DAB) kit (ZhongShan Golden Bridge Biotechnology, Beijing, China) according to the manufacturer's instructions. The sections were counterstained with hematoxylin, observed under a light microscope, and photographed. Negative controls were obtained for each section by omitting the primary antibody and by using pre-immune serum instead of the primary antiserum.

TNF- $\alpha$ induction Human omental adipose tissues were obtained from normal weight patients during abdominal surgery for appendicitis. The samples were processed as described previously ${ }^{[11]}$, and the minced adipose tissue fragments were placed in serum-free M199 (Invitrogen, USA) containing $25 \mathrm{mmol} / \mathrm{L}$ HEPES with or without increasing concentrations of TNF- $\alpha(5,50$, and $100 \mu \mathrm{g} / \mathrm{L}$; Sigma, St Louis, MO, USA). Cultures were maintained for $48 \mathrm{~h}$. At the end of culture, the tissues were rapidly washed in saline, frozen in liquid nitrogen, and stored at $-80{ }^{\circ} \mathrm{C}$ until the analysis. STEAP4 mRNA and protein expressions were determined by RT-PCR and an immunoblot analysis, respectively, as described earlier.

Statistical analysis All data are expressed as mean \pm SEM. Statistical analysis was performed using the paired Student's $t$-test of the SPSS 10.0 statistical software package (SPSS, Chicago, IL, USA). The threshold of significance was defined as $P<0.05$.

\section{Results}

Differential expression of STEAP4 in adipose tissue from obese patients and normal weight controls STEAP4
mRNA and protein expressions in human omental adipose tissues from obese patients and normal weight control were determined by RT-PCR and an immunoblot analysis, respectively. As shown in Figure 1, STEAP4 mRNA levels were lower in adipose tissue from obese patients relative to normal weight controls. The immunoblot analysis showed approximately a $52 \mathrm{kDa}$ band that corresponded to the predicted size of STEAP4 (data not shown). Moreover, STEAP4 protein levels were also lower in the adipose tissue from obese patients relative to the normal weight controls (Figure 2).
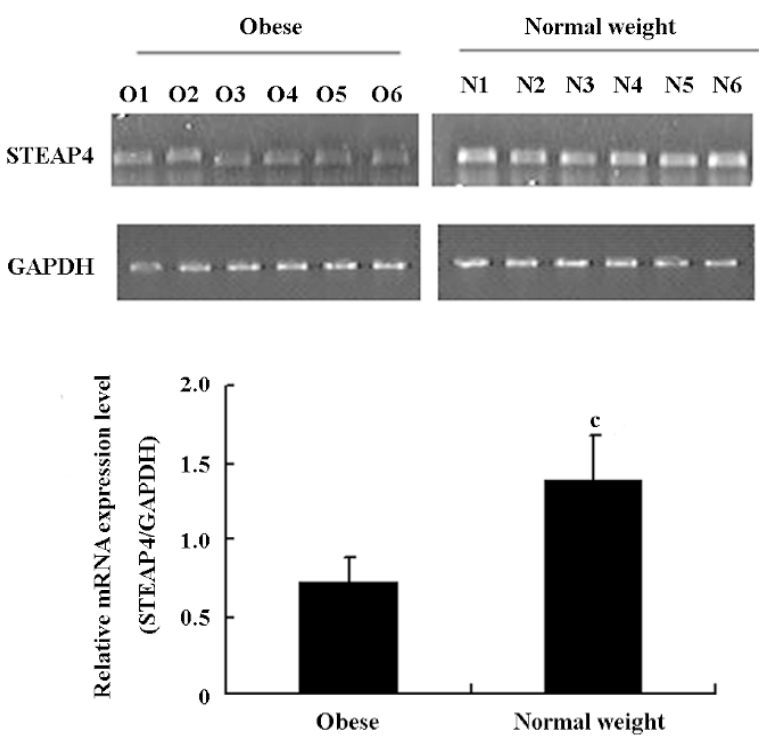

Figure 1. RT-PCR analysis shows the differential expression of STEAP4 mRNA in omental adipose tissue from obese patients relative to normal weight controls. STEAP4 mRNA levels were quantified and normalized to GAPDH mRNA levels. STEAP4 mRNA levels were significantly lower in obese patients relative to normal weight controls. $n=6$. ${ }^{\mathrm{c}} P<0.01$ vs normal weight controls. O, obese; $\mathrm{N}$, normal weight.

STEAP4 mRNA expression pattern in a panel of human tissues We performed RT-PCR using a panel of human cDNA samples to determine the tissue distribution of STEAP4 mRNA; this study included 11 human adult tissues. Figure 3 shows that among the human tissues tested, adipose tissue showed the highest levels of the STEAP4 expression, followed by placenta and lung. Lower levels of STEAP4 transcripts were detected in the skeletal muscle and kidney, whereas STEAP4 mRNA was undetectable in the spleen and brain.

STEAP4 protein localizes to the plasma membrane of adipocytes Because the subcellular localization of human STEAP4 protein in adipose tissue may provide key insights regarding STEAP4 function, we performed immunohis- 

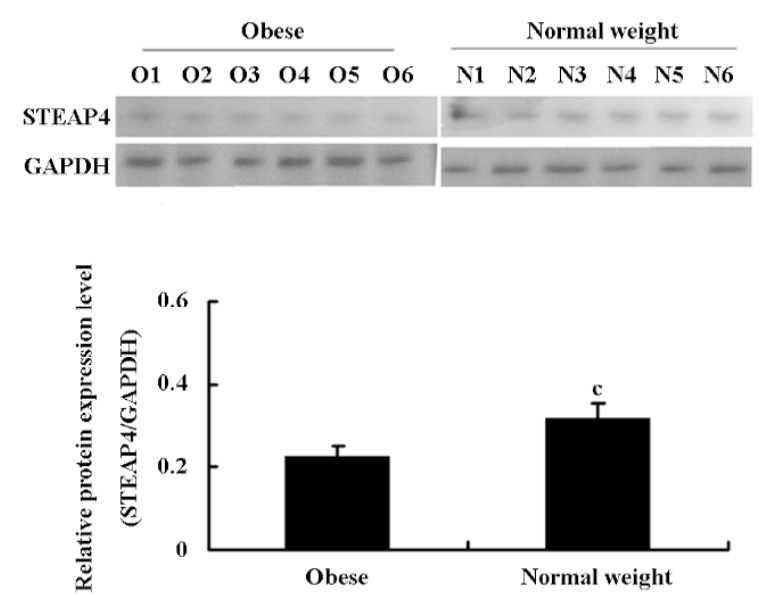

Figure 2. Downregulation of STEAP4 protein levels in obese patients relative to normal weight controls. STEAP4 protein levels in omental adipose tissue were determined by immunoblot analysis. STEAP4 protein levels were downregulated in obese patients relative to normal weight controls. $n=6 .{ }^{\mathrm{c}} P<0.01 \mathrm{vs}$ normal weight controls. $\mathrm{O}$, obese; $\mathrm{N}$, normal weight.
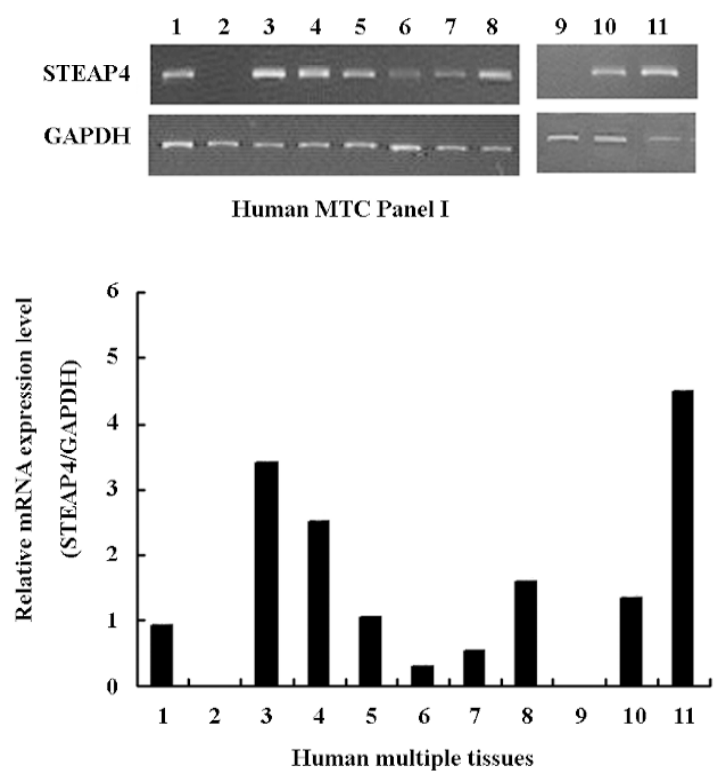

Figure 3. Analysis of STEAP4 expression in a panel of human tissues. STEAP4 mRNA levels were analyzed in a panel of human tissues using human MTC panel I and other human cDNA samples. STEAP4 mRNA levels were normalized to GAPDH for each tissue. Lane 1, heart; 2, brain; 3, placenta; 4, lung; 5, liver; 6, skeletal muscle; 7 , kidney; 8 , pancreas; 9 , spleen; 10, testis; and 11, omental adipose tissue.

tochemical analyses of human adipose tissue using antiSTEAP4 antibodies and HRP-conjugated secondary antibodies. Figure 4 shows that the STEAP4 protein localized to the plasma membrane of adipocytes, suggesting that

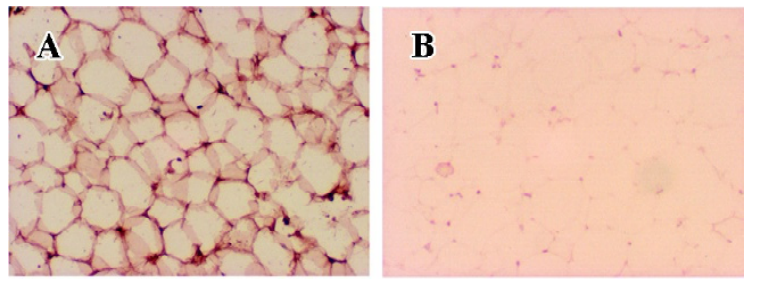

Figure 4. Immunohistochemical analysis of the STEAP4 expression in human adipose tissue. Human adipose tissue samples were fixed in $4 \%$ paraformaldehyde at $4{ }^{\circ} \mathrm{C}$ overnight and were embedded in paraffin. Sections were incubated with rabbit polyclonal antiSTEAP4 antibodies, followed by incubation with a goat antirabbit HRP-conjugated secondary antibody. Primary antibody was detected using a DAB kit, and sections were counterstained with hematoxylin. (A) STEAP4; (B) negative control. Magnification $\times 100$.

STEAP4 might be a membrane-associated protein.

TNF- $\alpha$-induced modulation of STEAP4 $\mathrm{mRNA}$ and protein expressions To determine whether the STEAP4 gene expression could be induced by TNF- $\alpha$, we examined the STEAP4 expression in primary cultures of adipose tissue treated with increasing levels of TNF- $\alpha$. As shown in Figure 5 , TNF- $\alpha$ led to a dose-dependent increase in the STEAP4 mRNA expression after $48 \mathrm{~h}$ of treatment. This effect was undetectable at $5 \mu \mathrm{g} / \mathrm{L} \mathrm{TNF}-\alpha$, and reached the maximum at $50 \mu \mathrm{g} / \mathrm{L}$; a half-maximal response was obtained at $100 \mu \mathrm{g} / \mathrm{L}$. Similarly, the STEAP4 protein expression also increased in response to TNF- $\alpha$ treatment. The treatment of cultured adipose tissue for $48 \mathrm{~h}$ with $50 \mu \mathrm{g} / \mathrm{L} \mathrm{TNF}-\alpha$ led to a stronger increase in the STEAP4 protein expression than that induced by $100 \mu \mathrm{g} / \mathrm{L} \mathrm{TNF}-\alpha$; this effect was undetectable in the presence of $5 \mu \mathrm{g} / \mathrm{L}$ TNF- $\alpha$ (Figure 6).

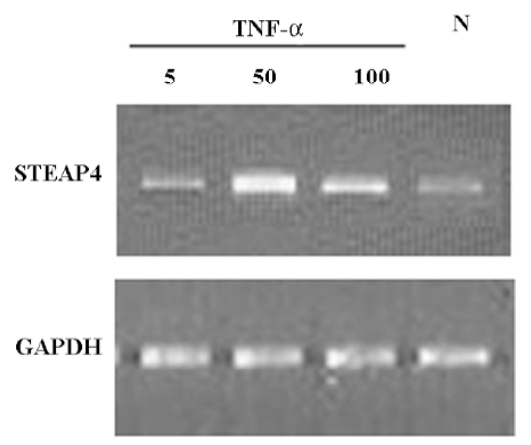

Figure 5. TNF- $\alpha$-mediated induction of the STEAP4 mRNA expression in cultured adipose tissue. Cultured human adipose tissues were treated with increasing concentrations of TNF- $\alpha$ for $48 \mathrm{~h}$. Total RNA was extracted from each sample, followed by RT-PCR analysis. Five microliters of PCR products were subjected to $1.5 \%$ agarose gel electrophoresis, and the resulting bands were visualized using ethidium bromide staining (N, without TNF- $\alpha$; 5: $5 \mu \mathrm{g} / \mathrm{L}$ TNF- $\alpha$; 50, $50 \mu \mathrm{g} / \mathrm{L}$ TNF- $\alpha ; 100,100 \mu \mathrm{g} / \mathrm{L}$ TNF- $\alpha$ ). 


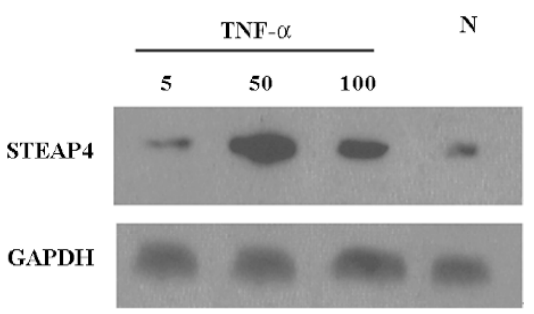

Figure 6. TNF- $\alpha$-mediated induction of the STEAP4 protein expression in cultured adipose tissue. Cultured human adipose tissues were treated with increasing concentrations of TNF- $\alpha$ for $48 \mathrm{~h}$. Protein lysates were subjected to SDS-PAGE, followed by immunoblot analysis using anti-STEAP4 and anti-GAPDH antibodies (N, without TNF- $\alpha$; $5,5 \mu \mathrm{g} / \mathrm{L}$ TNF- $\alpha ; 50,50 \mu \mathrm{g} / \mathrm{L}$ TNF- $\alpha ; 100,100 \mu \mathrm{g} / \mathrm{L} \mathrm{TNF}-\alpha)$.

\section{Discussion}

Obesity is a multifactorial disease resulted from interactions between susceptibility genes and environmental factors. The obesity gene map reveals that putative loci affecting obesity-related phenotypes are found on all autosomes and on the $\mathrm{Y}$ chromosome. The number of genes, markers, and chromosomal regions that have thus far been associated with or linked to obesity phenotypes has reached 200 and continues to increase ${ }^{[12]}$.

The mouse STAMP2 gene has been reported recently to play a role in the coordinated regulation of nutrient and inflammatory responses in adipose tissue ${ }^{[9]}$. However, a role for human STEAP4, the homolog of mouse STAMP2, in obesity has not been reported. In the present study, we found that the STEAP4 expression was downregulated in adipose tissue from obese human patients. Although our case number is only 6, STEAP4 downregulation occurred consistently at both the mRNA and protein levels. These findings suggest a close relationship between STEAP4 downregulation and obesity in humans. Moreover, we found that STEAP4 exhibited a tissue-specific pattern of expression pattern, and that STEAP4 is most highly expressed in human adipose tissue. Korkmaz et al showed that STEAP4 was expressed most highly in the placenta, lung, heart, and prostate among 16 different human tissues ${ }^{[7]}$; however, their study did not examine the STEAP4 expression levels in adipose tissue. We found that the STEAP4 expression was highest in adipose tissue, followed by the placenta, lung, and heart. Taken together, our results strongly support an active role for STEAP4 in adipose tissue and suggest that STEAP4 might contribute to obesity.

To explore further the role of STEAP4 in human adipose tissue, we confirmed that human STEAP4 exhibited a plasma membrane-associated pattern of localization in human adipocyte tissue. Furthermore, the STEAP4 expression was induced in a dose-dependent manner by TNF- $\alpha$ in cultured human adipose tissue. TNF- $\alpha$ exerts a well-established, key regulatory role in obesity and in obesity-related insulin resistance (IR ${ }^{[13]}$; TNF- $\alpha$ also markedly alters adipose tissue development and metabolism ${ }^{[14-17]}$. Overwhelming evidence suggests that TNF- $\alpha$ could regulate the expression of many obesity-related genes, including resistin, leptin, visfatin, adiponectin $^{[18-20]}$, and of particular interest, the mouse homolog of human STEAP4, STAMP2 ${ }^{[8]}$. Therefore, we hypothesized that STEAP4 might also be regulated by TNF- $\alpha$, in a manner similar to that of STAMP2. This would implicate STEAP4 as a key mediator of the physiological or pathological effects of TNF- $\alpha$, which may modulate several adipocyteassociated functions, including differentiation, lipolysis, lipogenesis, insulin sensitivity, and apoptosis. In the present study, we demonstrated that TNF- $\alpha$ treatment led to a dosedependent induction of the STEAP4 expression in cultured human adipose tissue, at both the mRNA and protein levels. However, it seemed to be contradictory that in obese patients with high serum TNF- $\alpha$ level, the STEAP4 expression level was lower than the normal controls. We considered although TNF- $\alpha$ was an important regulator of the STEAP4 expression in vitro, the STEAP4 expression may also be modulated by some other factors in vivo. The similar phenomenon was observed in the study of resistin, which is abundantly expressed in obesity but its expression could be suppressed by TNF- $\alpha$ in vitro ${ }^{[18,21]}$. Until now, the relationship between cytokines, such as TNF- $\alpha$ with the STEAP4 expression, remains an unresolved question. This work may make it a little clearer.

The identification of a STEAP4 N-terminal domain with associated nicotinamide-adenine dinucleotide phosphate (NADP) oxidoreductase coenzyme activity ${ }^{[7]}$ provides an interesting clue about potential STEAP4-associated biochemical functions. Taken together with previous studies, including the discovery that an NADPH-dependent $\mathrm{H}_{2} \mathrm{O}_{2}$ generating system was associated with human and rodent adipocyte plasma membranes ${ }^{[22,23]}$ and that reactive oxygen species (ROS) played a vital role in obesity and in obesityrelated $\mathrm{IR}^{[24]}$, these findings suggest that STEAP4 might be involved in the ROS-related pathological pathway and may eventually contribute to the development of obesity and obesity-related IR.

Our studies were based on recent findings by Wellen $e t$ al who systematically identified functional links between STAMP2 and obesity in mice. Our study focused on STEAP4, the human homolog of STAMP2. In conclusion, STEAP4 was abundantly expressed in human adipose tissue and that the STEAP4 expression was significantly downregulated in 
obese patients. Furthermore, STEAP4 underwent a dosedependent induction in response to TNF- $\alpha$ treatment. Collectively, these findings provide new insights into how the STEAP4 and TNF- $\alpha$ pathways may contribute to the development of obesity and obesity-related IR in humans.

\section{References}

1 Spiegelman BM, Flier JS. Obesity and the regulation of energy balance. Cell 2001; 104: 531-43.

2 Kahn BB, Flier JS. Obesity and insulin resistance. J Clin Invest 2000; 106: 473-81.

3 Visscher TL, Seidell JC. The public health impact of obesity. Annu Rev Public Health 2001; 22: 355-75.

4 Diatchenko L, Lau YF, Campbell AP, Chenchik A, Moqadam F, Huang B, et al. Suppression subtractive hybridization: a method for generating differentially regulated or tissue-specific cDNA probes and libraries. Proc Natl Acad Sci USA 1996; 93: 6025-30.

5 Diatchenko L, Lukyanov S, Lau YF, Siebert PD. Suppression subtractive hybridization: a versatile method for identifying differentially expressed genes. Methods Enzymol 1999; 303: 34980 .

6 Qiu J, Ni YH, Gong HX, Fei L, Pan XQ, Guo M, et al. Identification of differentially expressed genes in omental adipose tissues of obese patients by suppression subtractive hybridization. Biochem Biophys Res Commun 2007; 352: 469-78.

7 Korkmaz CG, Korkmaz KS, Kurys P, Elbi C, Wang L, Klokk TI, et al. Molecular cloning and characterization of STAMP2, an androgen-regulated six transmembrane protein that is overexpressed in prostate cancer. Oncogene 2005; 24: 4934-45.

8 Moldes M, Lasnier F, Gauthereau X, Klein C, Pairault J, Feve B. Tumor necrosis factor-alpha-induced adipose-related protein (TIARP), a cell-surface protein that is highly induced by tumor necrosis factor-alpha and adipose conversion. J Biol Chem 2001; 276: 33938-46.

9 Wellen KE, Fucho R, Gregor MF, Furuhashi M, Morgan C, Lindstad $\mathrm{T}$, et al. Coordinated regulation of nutrient and inflammatory responses by STAMP2 is essential for metabolic homeostasis. Cell 2007; 129: 537-48.

10 Wang B, Zhang M, Ni YH, Liu F, Fan HQ, Fei L, et al. Identification and characterization of NYGGF4, a novel gene containing a phosphotyrosine-binding (PTB) domain that stimulates 3T3-L1 preadipocytes proliferation. Gene 2006; 379: 132-40.

11 Fried SK, Moustaid-Moussa N. Culture of adipose tissue and isolated adipocytes. Methods Mol Biol 2001; 155:197-212.

12 Rankinen T, Zuberi A, Chagnon YC, Weisnagel SJ, Argyropoulos
G, Walts B, et al. The human obesity gene map: the 2005 update. Obesity (Silver Spring) 2006; 14: 529-44.

13 Tilg H, Moschen AR. Adipocytokines: mediators linking adipose tissue, inflammation and immunity. Nat Rev Immunol 2006; 6: $772-83$.

14 Winkler G, Kiss S, Keszthelyi L, Sápi Z, Ory I, Salamon F, et al. Expression of tumor necrosis factor (TNF)-alpha protein in the subcutaneous and visceral adipose tissue in correlation with adipocyte cell volume, serum TNF-alpha, soluble serum TNFreceptor-2 concentrations and C-peptide level. Eur J Endocrinol 2003; 149: 129-35.

$15 \mathrm{Xu} \mathrm{H}$, Uysal KT, Becherer JD, Arner P, Hotamisligil GS. Altered tumor necrosis factor-alpha (TNF-alpha) processing in adipocytes and increased expression of transmembrane TNF-alpha in obesity. Diabetes 2002; 51: 1876-83.

16 Hotamisligil GS, Budavari A, Murray D, Spiegelman BM. Reduced tyrosine kinase activity of the insulin receptor in obesitydiabetes: central role of tumor necrosis factor-alpha. J Clin Invest 1994; 94: 1543-9.

17 Krogh-Madsen R, Plomgaard P, Møller K, Mittendorfer B, Pedersen BK. Influence of TNF-alpha and IL-6 infusions on insulin sensitivity and expression of IL-18 in humans. Am J Physiol Endocrinol Metab 2006; 291: E108-14.

18 Shojima N, Sakoda H, Ogihara T, Fujishiro M, Katagiri H, Anai $\mathrm{M}$, et al. Humoral regulation of resistin expression in 3T3-L1 and mouse adipose cell. Diabetes 2002; 51: 1737-44.

19 Finck BN, Johnson RW. Tumor necrosis factor (TNF)-alpha induces leptin production through the p55 TNF receptor. Am J Physiol Regul Integr Comp Physiol 2000; 278: R537-43.

20 Hector J, Schwarzloh B, Goehring J, Strate TG, Hess UF, Deuretzbacher G, et al. TNF-alpha alters visfatin and adiponectin levels in human fat. Horm Metab Res 2007; 39: 250-5.

21 Ajala MW, Qi Y, Patel HR, Takahashi N, Banerjee R, Pajvani $\mathrm{UB}$, et al. Regulation of resistin expression and circulating levels in obesity, diabetes, and fasting. Diabetes 2004: 53: 1671-9.

22 Mukherjee SP, Lynn WS. Reduced nicotinamide adenine dinucleotide phosphate oxidase in adipocyte plasma membrane and its activation by insulin. Possible role in the hormone's effects on adenylate cyclase and the hexose monophosphate shunt. Arch Biochem Biophys 1977; 184: 69-76.

23 Krieger-Brauer HI, Kather H. Human fat cells possess a plasma membrane-bound $\mathrm{H}_{2} \mathrm{O}_{2}$-generating system that is activated by insulin via a mechanism bypassing the receptor kinase. J Clin Invest 1992; 89: 1006-13.

24 Eriksson JW. Metabolic stress in insulin's target cells leads to ROS accumulation--a hypothetical common pathway causing insulin resistance. FEBS Lett 2007; 581: 3734-42. 